\title{
miR-429 as biomarker for diagnosis, treatment and prognosis of cancers and its potential action mechanisms: A systematic literature review
}

\author{
Minireview
}

C. M. GUO', S. Q. LIU'2, M. Z. SUN ${ }^{1, *}$

${ }^{1}$ Department of Biotechnology, College of Basic Medical Sciences, Dalian Medical University, Dalian 116044, China; ${ }^{2}$ Department of Biochemistry, College of Basic Medical Sciences, Dalian Medical University, Dalian 116044, China

*Correspondence: smzlsq@163.com

Received April 1, 2019 / Accepted July 1, 2019

\begin{abstract}
miR-429 is a member of miR-200 family. Accumulated evidence has indicated that miR-429 dysregulation is involved in the epithelial-mesenchymal transition (EMT), progression, development, invasion, metastasis, apoptosis and drug resistance of a variety of cancers. miR-429 might specifically function either as a tumor suppressor or promoter candidate for certain cancers depending on the particular types of tumor cells/tissues. miR-429 appears to have a tumor-suppression role in renal cell carcinoma (RCC), breast cancer (BC), gastric carcinoma (GC), glioblastoma (GBM), esophageal cancer (EC), osteosarcoma, oral squamous cell carcinoma (OSCC), cervical cancer (CC), pancreatic cancer, tongue squamous cell carcinoma (TSCC), nephroblastoma, nasopharyngeal carcinoma (NPC) and soft tissue sarcomas. On the other hand, miR-429 has a tumor-promotion role in endometrial cancer (EmCa), prostate cancer $(\mathrm{CaP})$ and lung cancer (LC). However, miR-429 shows paradoxical role in colorectal cancer (CRC), hepatocellular carcinoma (HCC), bladder cancer and ovarian cancer (OC). This article summarizes the associations between miR-429 and malignant tumors as well as potential action mechanisms. miR-429 has a potential to be used in the future as a biomarker for the diagnosis, treatment and prognosis of certain cancers.
\end{abstract}

Key words: miR-429, cancer, target genes

MicroRNAs (miRNAs) are 18-24 nucleotides-long small non-coding RNAs that negatively regulate gene expression by directly degrading mRNA or suppressing post-transcriptional protein translation by binding to the 3 '-untranslated region (3'-UTR) of targeted mRNAs $[1,2]$. miRNAs are involved in cell development, differentiation, apoptosis, proliferation, metastasis and metabolism of crucial biological processes [3]. Especially, miRNAs dysregulation is also involved in a wide range of human cancers, functioning as tumor promoter or suppressor in tumorigenesis [4-6].

miR-429 belongs to the miR-200 family, which includes miR-200a, miR-200b, miR-200c, miR-141 and miR-429, and is located on chromosome 1 [7]. Accumulated evidence has indicated that miR-429 dysregulation is involved in the epithelial-mesenchymal transition (EMT), progression, development, invasion, metastasis, apoptosis and drug resistance of various cancers [8-11]. miR-429 is relevant to tumorigenesis in a tumor type-specific pattern, and might function either as a tumor suppressor or promoter candidate for certain cancers depending on the particular type of tumor cells/tissues [12-15]. The research evidences in recent years indicated that miR-429 could regulate tumor malignant behavior by targeting ZEB1, ZEB2, Sp1, BMI, E2F3, KIAA0101, PAK6, Onecut2, SOX2, Bcl-2, BMK1, XIAP, c-myc, SP1, PTEN, RASSF8, TIMP2, DLC-1, p27Kip1, NOTCH1, CRKL molecules, etc. [8-15].

This article summarizes the associations between miR-429 and malignant tumors, as well as potential action mechanisms in recent years. The study obtained on it has led to a renewed interest in potential role and mechanism of miR-429 deregulation in cancer, which might potentially provide novel insight of miR-429 deregulation in tumor research. 


\section{miR-429 downregulation in cancers}

The miR-429 expression level is negatively correlated with renal cell carcinoma (RCC), breast cancer (BC), gastric carcinoma (GC), glioblastoma (GBM), esophageal cancer (EC), osteosarcoma, oral squamous cell carcinoma (OSCC), cervical cancer (CC), pancreatic cancer, tongue squamous cell carcinoma (TSCC), nephroblastoma, nasopharyngeal carcinoma (NPC) and soft tissue sarcomas, as summarized in Table 1. miR-429 is a negative indicator for the development, progression, prognosis, proliferation, metastasis, apoptosis and drug resistance of these types of cancers.

Renal cell carcinoma. miR-429 expression level was associated with development, progression and prognosis of RCC. miR-429 was significantly downregulated in RCC tissues compared to paired adjacent nontumorous tissues, moreover, decreased expression of miR-429 positively associated with higher grade, higher TNM stage, lymph node metastasis (LNM), shorter disease-free (SDF) and overall survival (OS) of RCC patients, suggesting the lower expression of miR-429 is associated with more aggressive cancer [16-17]. Meanwhile, miR-429 expression in RCC ACHN and A498 cells was lower than in normal renal cell HK-2 [16-17]. The detection of miR-429 expression levels may assist in clinical diagnosis and prognosis of RCC.

miR-429 contributed to viability, migration and invasion abilities of RCC cells. miR-429 overexpression inhibited proliferation, colony formation, migration and invasion abilities of RCC cells ACHN, SGC-7901, 786-O and A498, vice versa, miR-429 low expression promoted growth and metastasis of these RCC cells $[16,18]$. In addition, miR-429 overexpression downregulated Sp1 and c-myc protein expression [18], meanwhile, miR-429 could also directly target BMI1-3'-UTR and E2F3-3'-UTR to regulate E-cadherin, $\mathrm{N}$-cadherin, Vimentin, p14 and p16 expression in RCC [16]. The above results revealed a tumor suppressive role of miR-429 through direct targeting Sp1, c-myc, BMI1 and E2F3 in RCC. miR-429 may serve as a predictive marker in RCC.

Breast cancer. miR-429 was associated with development, progression and LNM of BC. miR-429 was downregulated in BC tissues compared with normal adjacent tissues, the tumors with LNM showed distinctly lower expression of miR-429 than that without LNM. miR-429 had also low expression in tumor tissues with higher numbers of LNM. However, miR-429 expression level was not associated with patient age, tumor size, hormone receptor status, Her-2 status and histological grad [19]. miR-429 downregulation was acquired in tumor metastatic potential and miR-429 might be useful to estimate the likelihood of the presence of pathologically positive lymph nodes.

miR-429 was involved in proliferation, migration, invasion of BC cells. miR-429 overexpression remarkably suppressed proliferation, migration and invasion abilities of MDA-MB231 cells in vitro [20, 21]. Moreover, decreased expression of miR-429 was involved in negatively regulating bone metas- tasis of BC cells by establishing an in vivo bone metastasis model of BC via injecting MDA-MB-231 cells into the left ventricle of nude mice [20]. Furthermore, miR-429 significantly reduced ZEB1, CRKL and LIMK1 expression levels in MDA-MB-231 cells, indicating miR-429 might inhibit migration and invasion of $\mathrm{BC}$ cells potentially by targeting ZEB, CRKL and LIMK1 [20, 21].

miR-429 could regulate MDA-MB-231 cell apoptosis. miR-429 was upregulated in MDA-MB-231 and MDA-MB468 cells after treatment with $\delta$-tocotrienol, while miR-429 inhibition partially rescued the apoptosis induced by $\delta$-tocotrienol in MDA-MB-231 cells. Meanwhile, miR-429 overexpression induced MDA-MB-231 cell apoptosis. Furthermore, $\mathrm{X}$-linked inhibitor of apoptosis protein (XIAP) is a target gene of miR-429, and miR-429 could mediate $\delta$-tocotrienol-induced apoptosis in triple-negative BC cells by targeting XIAP. The activation of miR- 429 by $\delta$-tocotrienol may be an effective novel strategy for prevention and treatment of BC [22].

Gastric cancer. miR-429 was involved in development and progression of GC. The expression level of miR-429 was lower in GC tissues than that in adjacent non-tumor gastric tissues [23]. Moreover, miR-429 expression levels were lower in advanced stage tumors compared to early stage tumors [8]. Furthermore, miR-429 expression levels in patients' tumor tissue with LNM were significantly lower than in those without LNM [8]. The results suggested miR-429 played an important role in the pathogenesis of GC and might function as a recessive cancer gene.

miR-429 was associated with metastasis of GC. miR-429 overexpression inhibited migration and invasion abilities of GC cells SGC-7901, AGS, SUN-16, BGC-823, and on the contrary, miR-429 lower expression promoted its migration and invasion abilities $[23,24]$. Meanwhile, miR-429 also directly targeted Sp1 in SGC-7901, AGS cells [24]. Taken together, miR-429 downregulation promoted Sp1-mediated GC cell migration and invasion. miR-429 was implicated in proliferation of GC. miR-429 overexpression inhibited proliferation of SGC-7901 and BGC823 cells in vitro and in vivo, while, miR-429 downregulation promoted proliferation of SGC-7901 and BGC823 cells [25, 26]. miR-429 direct targeting FSCN1-3'-UTR suppresses its expression, and FSCN1 knockdown mimics the effects of miR-429 overexpression, thus leading to the growth defect of SGC-7901 cells. Furthermore, FSCN1 overexpression markedly counteracted the inhibition effect of miR-429 on SGC-7901 cells growth. Moreover, FSCN1 expression level was negatively correlated with miR-429, indicating miR-429 inhibited GC cells proliferation by targeting FSCN1 [25]. miR-429 serves as a tumor suppressor during tumorigenesis and may be a potential therapeutic target of GC.

miR-429 was implicated in apoptosis of GC. miR-429 was significantly decreased and Bcl-2 was increased in GC specimens compared to the paired adjacent non-tumor gastric tissue. Moreover, the expression levels of miR-429 inversely 
Table 1. Negative correlation of miR-429 with cancers.

\begin{tabular}{ll}
\hline Tumor type & Expression pattern \\
\hline Renal cell carcinoma & miR-429 is downregulated in \\
RCC tissue and cells compared \\
to paired adjacent nontumorous \\
tissue and normal renal cells. \\
\\
miR-429 is downregulated in \\
BC tissue compared to nor- \\
mal adjacent tissue, and down \\
expressed in tumor tissues with \\
higher numbers of lymph node \\
metastasis.
\end{tabular}

Gastric cancer (GC)

Glioblastoma (GBM)

Esophageal cancer (EC) miR-429 is downregulated in EC tissue compared to adjacent nonneoplastic tissue.

Osteosarcoma

Oral squamous cell carcinoma (OSCC)

Cervical cancer (CC)

Tongue squamous cell carcinoma (TSCC)

Nephroblastoma

Nasopharyngeal carcinoma

Soft tissue sarcomas

miR-429 is downregulated in GC, advanced stage tumor, lymph node metastasis tumor tissue compared to adjacent non-tumor gastric, early stage tumor, without lymph node metastasis tumor tissue.

miR-429 is downregulated in GBM tissue and cells compared to normal tissue and cells. miR-429 is downregulated in osteosarcoma tissue and cells compared to the adjacent normal tissue and normal cells.

miR-429 is downregulated in OSCC tissue compared with matched tumor-adjacent normal oral tissue.

miR-429 is downregulated in CC tissues and cells compared with normal tissues and cells.

miR-429 is downregulated in gemcitabine-resistant pancreatic with original cell SW1990.

miR-429 is downregulated in TSCC tissues and cells compared with adjacent nontumor tissues and keratinocyte cells.

miR-429 is downregulated in nephroblastoma tissues and cells comparing with adjacent normal tissues and HEK-293T cells.

miR-429 is downregulated in NPC-derived cells compared with immortalized NPC cells; miR-429 is downregulated in poorly-differentiated CNE-2 cells compared with well-differentiated CNE-1 cells.

Implication

\section{Implication}

miR-429 expression level is negatively

correlated with progression and prognosis of RCC; miR-429 is associated with proliferation, colony formation, migration and invasion abilities of RCC cells.

miR-429 is associated with development, progression, proliferation, migration, invasion, LNM and apoptosis of BC.

miR-429 is associated with development, progression and prognosis of GBM; miR-429 is involved in the proliferation, apoptosis, migration, invasion and apoptosis of GBM.

miR-429 is relevant to the development, progression, occurrence, lymph node metastasis, differentiation of NPC; miR429 overexpression significantly inhibits proliferation, migration, invasion and promoted apoptosis of EC cells.

High level of miR-429 is associated with high OS rate of patients; miR-429 overex-

pression inhibits proliferation, migration, invasion and promoted apoptosis of osteosarcoma cells.

miR-429 downregulation correlated with progression and malignant proliferation of OSCC.

miR-429 deregulation is associated with the proliferation, apoptosis, migration and invasion of CC cells. cancer cell SW1990/GZ compared

miR-429 involved in drug resistance of pancreatic cancer and miR-429 could alleviate PNI of pancreatic cancer.

miR-429 overexpression suppresses cell cycle, proliferation and migration of TSCC cells; low miR-429 expression was positively associated with poor OS.

miR-429 overexpression inhibits proliferation, promotes apoptosis and arrests cell cycle of G401 cells in G0/G1 phase.

miR-429 is associated with differentiation, proliferation, migration and invasion of nasopharyngeal carcinoma

Mechanism
miR- 429 plays a tumor suppressor
role in RCC by directly targeting Sp1,

Ref c-myc, BMI1 and E2F3.

miR-429 inhibits BC cell migration and invasion potentially by targeting ZEB1, CRKL and LIMK1; miR-429 mediates $\delta$-tocotrienol-induced apoptosis of BC cells by targeting XIAP.

miR-429 inhibits Sp1-mediated GC cell migration and invasion; miR-429 inhibited GC cells proliferation by targeting FSCN1; miR-429 induces a GC cell apoptosis by Bcl-2.

miR-429 inhibits migration and invasion of GBM cells by suppressing BMK1 expression; miR-429 induces apoptosis and proliferation of GBM cell via Bcl-2 and SOX2.

miR-429 regulates malignant behavior 31 of EC cells by targeting Bcl-2 and

SP-1.

miR-429 serves as a tumor suppressor via interaction with ZEB1 in osteosarcoma.

miR-429 inhibits OSCC growth by targeting ZEB1.

miR-429 suppresses proliferation targeting IKK $\beta$ via regulating NF- $\kappa \beta$ pathway; miR-429 suppresses invasion and migration of $\mathrm{CC}$ cells by targeting ZEB1 and CRKL.

miR-429 enhances gemcitabine sensitivity via regulating PDCD4 in pancreatic cancer cells; miR-429 potentially suppresses neurotrophin-3 to alleviate PNI of PDAC

Long noncoding RNA GIHCG enhances TSCC progression through regulating miR-429.

miR-429 regulates proliferation and apoptosis of nephroblastoma cell through targeting c-myc.

miR-429 inhibits migration and invasion of CNE- 2 cells by negatively modulating ZEB1 and CRKL.

miR-429 overexpression inhibits proliferation, colony formation, migration and invasion of fibrosarcoma cells.
miR-429 regulates fibrosarcoma cell malignant behavior by targeting KIAA0101. fibrosarcoma cell compared to normal cells. 
correlated with Bcl-2 in GC specimens. miR-429-low subjects had an inferior overall survival compared to miR-429-high subjects. Meanwhile, miR-429 overexpression inhibited Bcl-2-mediated cell survival against apoptosis induced by fluorouracil, while miR-429 depletion augmented it [27]. miR-429 may enhance GC cell apoptosis during chemotherapy.

Glioblastoma. miR-429 was associated with development and progression of glioma. miR-429 was significantly decreased in GBM specimens compared to paired adjacent non-tumor brain tissues. Meanwhile, miR-429 closely correlated with OS of GBM patients, low-miR-429 GBM patients had a significantly shorter OS compared to high-miR-429 GBM patients [28,29]. Moreover, the expression level of miR-429 was lower in glioma cells U87, U251, SHG44, A172 than that in human brain normal astrocytes cell NHA, HA1800 [28-30]. Thus, miR-429 may be useful prognostic marker and novel therapeutic target for GBM.

miR-429 was involved in migration and invasion of GBM cell. miR-429 overexpression inhibited migration and invasive abilities of U87 cell in vitro and in vivo. miR-429 direct targeting BMK1-3'-UTR suppressed its expression, moreover, miR-429 expression level was negatively correlated with BMK1 expression in glioma cells/tissues. Furthermore, BMK1 could negate the effects of miR-429 overexpression on U87 cell migration and invasion [28]. The results indicated that miR-429 inhibited migration and invasion of glioma cell by suppressing BMK1 expression.

miR-429 could inhibit proliferation and promote apoptosis of GBM cell [29]. miR-429 overexpression inhibited proliferation and promoted temozolomide-induced apoptosis of A172 cells, whereas, miR-429 downregulation promoted proliferation and inhibited temozolomide-induced apoptosis of A172 cells. Moreover, the expression levels of miR-429 and Bcl-2, SOX2 inversely correlated in GBM specimens, and miR-429 targeted the Bcl-2- and SOX2-3'-UTR to inhibit its translation, indicating that miR-429 inhibited proliferation and induced apoptosis of glioma cell through regulating Bcl-2 and SOX2 expression [29]. miR-429 overexpression may enhance chemotherapy outcome of GBM patients.

Esophageal cancer. miR-429 was involved in development and progression of EC. miR-429 expression level was lower in EC tissues than those in adjacent non-neoplastic tissues. The relatively low expression of miR-429 was significantly associated with the occurrence of LNM, differentiation status and TNM stage, however, there were no significant correlations between miR-429 expression and either gender, age or tumor location [31]. miR-429 may serve as a therapeutic target in EC.

miR-429 could regulate malignant behavior of EC cells. miR-429 overexpression significantly inhibited proliferation, migration, invasion and promoted apoptosis of EC9706 and KYSE30 cells. miR-429 could directly bind to $\mathrm{Bcl}-2$ - and SP1-3'-UTR to reduce their expression. Furthermore, Bcl-2 overexpression restored the pro-apoptotic function and SP-1 overexpression restored the anti-migration and anti-invasion function of miR-429 on EC9706 and KYSE30 cells [31], indicating miR-429 regulated malignant behavior of EC cells by targeting Bcl-2 and SP-1.

Osteosarcoma. miR-429 might play an important role in the pathogenesis of osteosarcoma. miR-429 was downregulated in osteosarcoma tissues and MG63, HOS, Saos2, U2OS cells compared to adjacent normal tissues and osteoblasts Hfob 1.19 cell [10, 32]. High expression level of miR-429 was associated with high OS rate of osteosarcoma patients [32]. miR-429 affected proliferation, apoptosis, migration and invasion of osteosarcoma cells. miR-429 overexpression inhibited proliferation, migration, invasion and promoted apoptosis of U2OS, SAOS, MG63 cells [10, 32], moreover, there was an inverse correlation between ZEB1 and miR-429 expression in osteosarcoma tissues. Furthermore, ZEB1 overexpression reversed the inhibitory effects of miR-429 on osteosarcoma cells behavior [10,32], indicating miR-429 might serve as a tumor suppressor to regulate progression and metastasis of osteosarcoma via interaction with ZEB1.

Oral squamous cell carcinoma. miR-429 correlated with progression and proliferation of OSCC. miR-429 was downregulated in OSCC tissues compared with matched tumor-adjacent normal oral tissues, moreover, miR-429 overexpression inhibited proliferation of OSCC cells SCC-25 and CAL27, vice versa. Furthermore, miR-429 could inhibit ZEB1 expression and the expression levels of miR-429 was negatively correlated with ZEB1 OSCC tissues [33], indicating miR-429 inhibited OSCC growth by targeting ZEB1. miR-429 played a tumor suppressor role in OSCC development.

Cervical cancer. $\mathrm{miR}-429$ as a tumor suppressor is involved in development, proliferation and apoptosis of CC. miR-429 was downregulated in CC tissues and CC cells C33A, HeLa, CaSki, SiHa compared with normal tissues and noncancerous ectocervical epithelial cell Ect1/E6E7. Meanwhile, miR-429 overexpression suppressed proliferation and promoted apoptosis of CC cells $[34,35]$. IKK $\beta$ was a target gene of miR-429 and ectopic expression of IKK $\beta$ abrogated the phenotypes induced by miR-429. Meanwhile, NF- $\kappa \beta$ pathway was activated when IKK $\beta$ was inhibited by miR-429 [34], indicating miR-429 suppressed proliferation and induced apoptosis of CC cell by targeting IKK $\beta$ via regulating NF- $\kappa \beta$ pathway.

miR-429 deregulation was associated with migration and invasion of CC cells. miR-429 overexpression inhibited migration and invasion of CC cells CaSki, SiHa in vitro and in vivo, vice versa. Remarkably, the expression levels of ZEB1 and CRKL were inversely associated with miR-429 in CaSki, SiHa cells, and miR-429 significantly inhibited their expression. Then, ZEB1 activated CHK1 via CRB3 upregulation. On the other hand, both ZEB1 and CRKL could impede NEED4L expression, and NEED4L downregulation increased SMAD2/SMAD3 expression level. miR-429, as a novel target, could suppress invasion and migration of CC cells by 
targeting ZEB1 and CRKL [36]. Taken together, miR-429 is a novel potential therapeutic target for CC patients.

Pancreatic cancer. miR-429 was involved in drug resistance of pancreatic cancer. miR-429 was downregulated in gemcitabine-resistant pancreatic cancer cell SW1990/GZ compared with original cell SW1990, meanwhile, miR-429 overexpression increased the SW1990/GZ cell sensibility to gemcitabine. miR-429 also suppressed SW1990 cells growth derived from xenograft tumor in the presence of gemcitabine and significantly enhanced the inhibition effect of gemcitabine [37]. Functionally, miR-429 could enhance gemcitabine sensitivity of pancreatic cancer cells via regulating PDCD4 expression [37], which might offer a novel therapeutic target for the chemotherapy resistance in pancreatic cancer.

miR-429 could alleviate perineural invasion (PNI) of pancreatic cancer. miR-429 was significantly decreased in pancreatic ductal adenocarcinoma (PDAC) tissues compared with normal pancreatic tissues, and it was profoundly decreased in tumor tissues presenting PNI compared to that in non-PNI tissues. Besides, miR-429 expression was gradually reduced with the TNM stages, and it showed significantly lower expression in stage III-IV patients than that in stage I-II. Meanwhile, miR-429 was significantly downregulated in PDAC cells MIA PaCa-2, BxPC-3, PANC-1, CAPAN-2, HAPC, Panc 03.27, Panc 04.03, Panc 05.04, Panc 08.13 compared with normal human pancreatic duct epithelial (HPDE) cell. Functionally, miR-429 overexpression significantly suppressed proliferation and invasion of MIA PaCa-2 and BxCP3 cells. miR-429 could directly bind to the 3'-UTR of NT-3 gene, when co-culturing the two PDAC cells with PC-12 cells, the invaded PDAC cell counts significantly increased comparing with the sole culture of PDAC cells. However, miR-429 overexpression or NT-3 blocking retarded the PDAC cell invasion in the co-culture system. PDAC cells conditioned medium (CM) treatment significantly increased the neurite outgrowth percentage in PC-12 cells, which was suppressed by culturing with CM from miR-429 mimics-transfected cells. In the CM cultured PC-12 cells, NT-3 receptor TrkC as well as pain-related proteins TRPV1 and TRPV2 were significantly elevated [38]. Collectively, miR-429 potentially suppressed neurotrophin-3 to alleviate PNI of PDAC.

Tongue squamous cell carcinoma. miR-429 played a vital role in TSCC progression. miR-429 was downregulated in TSCC tissues compared with adjacent nontumor tissues, low miR-429 expression was positively associated with poor OS. Meanwhile, miR-429 had a lower expression in human TSCC cell lines UM1, SCC1, SCC4, Cal27 compared with oral keratinocyte cell line NHOK. In addition, miR-429 overexpression suppressed cell cycle, proliferation and migration of TSCC cells. Furthermore, long noncoding RNA GIHCG could enhance TSCC progression through regulating miR-429 [39].

Nephroblastoma. miR-429 might function as a potential therapeutic target for the treatment of nephroblastoma.
miR-429 expression was remarkably lower in nephroblastoma tissues and G401 cells comparing with adjacent normal tissues and HEK-293T cells. miR-429 overexpression inhibited proliferation, promoted apoptosis and arrested cell cycle of G401 cells in G0/G1 phase. Furthermore, c-myc, the potential downstream target gene of miR-429, could reverse the biological effects of miR-429 on G401 cells [40], indicating miR-429 regulates proliferation and apoptosis of nephroblastoma cell through targeting c-myc.

Nasopharyngeal carcinoma. miR-429 might act as a negative regulatory factor of NPC tumorigenesis. miR-429 was markedly downregulated in NPC-derived CNE-1 and CNE-2 cells compared with immortalized NPC NP69 cells, it was also significantly downregulated in poorly-differentiated CNE-2 cells compared with well-differentiated CNE-1 cells. In addition, CNE- 1 and CNE- 2 cells exhibited higher growth rates compared with the NP69 cells, moreover, the CNE-2 cells exhibited higher proliferation rates compared with the CNE-1, indicating miR-429 expression level negatively associated with higher malignancy potential of NPC cells. Meanwhile, miR-429 overexpression inhibited migration and invasion of CNE-2 cells by negatively modulating ZEB1 and CRKL [41]. miR-429 may serve as a potential candidate for miRNA-based prognosis and therapy against NPC.

Soft tissue sarcomas. miR-429 was downregulated and KIAA0101 was upregulated in fibrosarcoma HT1080 cell line compared to normal cells IMR-90-tert and WI-38. Meanwhile, miR-429 overexpression inhibited proliferation, colony formation, migration and invasion of HT1080 cells, KIAA0101, a direct target of $\mathrm{miR}-429$, rescued the inhibition effect of miR-429 overexpression on HT1080 cells malignant behavior [42]. miR-429 acts as an anti-tumor miRNA via directly mediating KIAA0101.

\section{miR-429 upregulation in tumors}

Correspondingly, miR-429 is supposed to be a tumor promoter gene/protein. $\mathrm{miR}-429$ is positively associated with development, progression, metastasis and drug resistance of endometrial cancer $(\mathrm{EmCa})$, prostate cancer $(\mathrm{CaP})$ and lung cancer (LC), as summarized in Table 2. miR-429 was suggested as a potential therapeutic target for these types of cancers.

Endometrial carcinoma. miR-429 might play important role in development and drug resistance of EmCa. miR-429 was upregulated in EmCa tissues compared with normal endometrial tissues [13, 43, 44], moreover, miR-429 low expression significantly inhibited the growth of EmCa cells HEC-1A and Ishikawa. Furthermore, miR-429 was implicated in EmCa drug resistance. miR-429 low expression enhanced the cytotoxicity of cisplatin on HEC-1A cells [43], providing the direct evidence for the potential role of miR-429 in drug resistance of EmCa cells. miR-429 might offer new candidate target to be exploited in therapeutic strategies for EmCa patients. 
Table 2. Positive correlation of miR-429 with cancers.

\begin{tabular}{|c|c|c|c|c|}
\hline Tumor type & Expression pattern & Implication & Mechanism & Ref \\
\hline $\begin{array}{l}\text { Endometrial carcinoma } \\
(\mathrm{EmCa})\end{array}$ & $\begin{array}{l}\text { miR- } 429 \text { is upregulated in } \mathrm{EmCa} \\
\text { tissue compared to normal } \\
\text { endometrial tissue. }\end{array}$ & $\begin{array}{l}\text { miR- } 429 \text { expression level is positively } \\
\text { correlated with development, progres- } \\
\text { sion, proliferation and drug resistance } \\
\text { of EmCa. }\end{array}$ & & $13,43,44$ \\
\hline Prostate cancer $(\mathrm{CaP})$ & $\begin{array}{l}\text { miR- } 429 \text { is upregulated in the } \\
\text { human CaP cells compared with } \\
\text { the normal prostate epithelial } \\
\text { tissue. }\end{array}$ & $\begin{array}{l}\text { miR- } 429 \text { is involved in progression, } \\
\text { development and proliferation of } \mathrm{CaP} \text { as } \\
\text { a putative tumor promoter gene. }\end{array}$ & $\begin{array}{l}\text { miR- } 429 \text { acts as a novel oncogene } \\
\text { promoted CaP cell proliferation by } \\
\text { targeting } 227^{\text {Kip } 1} \text {. }\end{array}$ & 45 \\
\hline Lung cancer (LC) & $\begin{array}{l}\text { miR- } 429 \text { is upregulated in LC } \\
\text { tumor tissue and cells compared } \\
\text { to adjacent normal lung tissue } \\
\text { and normal lung cells. }\end{array}$ & $\begin{array}{l}\text { miR- } 429 \text { is associated with development, } \\
\text { progression and TNM stage of LC; miR- } \\
429 \text { is involved in proliferation, migra- } \\
\text { tion, invasion and drug resistance of LC. }\end{array}$ & $\begin{array}{l}\text { miR- } 429 \text { promotes proliferation of } \\
\text { LC cell by directly inhibiting DLC- } 1 \\
\text { expression; miR- } 429 \text { promotes migra- } \\
\text { tion and invasion of LC cell by directly } \\
\text { targeting PTEN, RASSF8 and TIMP } 2 \text {. }\end{array}$ & $46-49$ \\
\hline
\end{tabular}

Prostate cancer. miR-429 was involved in progression, development and proliferation of $\mathrm{CaP}$ as a putative tumor promoter gene. miR- 429 was significantly upregulated in $\mathrm{CaP}$ cells IF11 and IA8 compared with normal prostate epithelial tissues. miR-429 downregulation inhibited IF11 and IA8 cells proliferation and arrested in the G1 phase of cell cycle. Furthermore, p2 $7^{\text {Kip1 } 1}$ was a direct target of miR-429, p27 $7^{\text {Kip } 1}$ overexpression partially rescued the proliferation-promoting effect of miR-429 on IA8 cells [45]. In conclusion, miR-429 might be act as a novel oncogene promoted CaP cell proliferation by targeting $\mathrm{p} 27^{\mathrm{Kip} 1}$.

Lung cancer. miR-429 was associated with development and progression of LC. miR-429 was upregulated in LC tumor tissues compared to adjacent normal lung tissues, meanwhile, miR- 429 was discovered to be associated with TNM stage [46, 47]. Furthermore, miR-429 expression level was also significantly increased in LC cells A549, H23, H522, H1299, H2126 compared to normal lung cell MRC-5 [47], indicating miR-429 was a potential target for LC therapy.

miR-429 was involved in LC cell proliferation. miR-429 overexpression promoted H1229 and A549 cells proliferation abilities, while miR-429 downregulation inhibited its proliferation [47, 48]. Moreover, miR-429 could directly bind to DLC-1-3'-UTR to inhibit its expression in H1229 cells, while miR-429 knockdown promoted DLC-1 expression. In addition, DLC-1 overexpression not only inhibited H1229 cell proliferation, but also additionally reversed the promoting effect of miR-429 overexpression on H1229 cell proliferation. miR-429 may have an oncogenic role in the regulation of LC cell proliferation by directly inhibiting DLC-1 expression [48]. Therefore, miR-429 presented a putative therapeutic target for treatment of LC growth.

miR-429 affected migration and invasion of LC cells. miR-429 overexpression significantly promoted A549 cells migration and invasion abilities, whereas miR-429 downregulation inhibited these effects. Furthermore, miR-429 downregulated PTEN, RASSF8 and TIMP2 expression by directly targeting the 3'-UTR of these target genes in A549 cells [47]. Taken together, miR-429 might play an important role in promoting $\mathrm{LC}$ cells metastasis.

miR-429 was also associated with drug resistance of LC. The expression level of miR-429 was higher in the nintedanib-sensitive cells PC-1, QG56, LK-2, EBC-1, PC-9 than in the resistant cells A549, SQ5, PC-3, LC-1/sq, LC-2/ad. PC-1R was nintedanib-resistant PC-1 cell established by PC-1 continuous exposure to increasing concentrations of nintedanib in a stepwise manner, and miR-429 expression level was significantly decreased in PC1-R cells compared to PC- 1 cells [49]. miR-429 combined with nintedanib might be a novel potential therapeutic strategy for LC patients.

\section{Paradoxical roles of miR-429 in certain tumors}

Interestingly, the exact role of miR-429 is unclear in colorectal cancer (CRC), hepatocellular carcinoma (HCC), bladder cancer and ovarian cancer (OC), as summarized in Table 3. It behaves both as a tumor suppressor gene/protein and tumor promoter gene/protein in the same types of cancers.

\section{Colorectal cancer}

miR-429 downregulation in CRC. miR-429 acted as a tumor suppressor in the development and progression of CRC. miR-429 had a dynamic expression pattern during CRC progression stage, and was significantly downregulated in stage II and III tissues compared with corresponding adjacent normal colorectal mucosa tissues [50], and was also reduced in CRC cells SW620, LOVO compared to normal colon epithelial cell HCEpiC [51]. Meanwhile, the low expression of miR-429 was correlated with poor prognosis, lower overall disease-free survival and poorer differentiation of CRC patients [50]. Moreover, miR-429 deregulation played a relevant role in the development of CRC liver metastasis, 
Table 3. Paradoxical roles of miR-429 with cancers.

\begin{tabular}{|c|c|c|c|c|}
\hline Tumor type & Expression pattern & Implication & Mechanism & Ref \\
\hline $\begin{array}{l}\text { Colorectal cancer } \\
\text { (CRC) }\end{array}$ & $\begin{array}{l}\text { Downregulation: miR- } 429 \text { is down- } \\
\text { regulated in stage II, stage III, liver } \\
\text { metastatic tissue and CRC cells com- } \\
\text { pared to normal colorectal mucosa, } \\
\text { paired primary CRC tissue and normal } \\
\text { colon epithelial cells. } \\
\text { Upregulation: miR-429 is upregulated } \\
\text { in CRC tissue compared to adjacent } \\
\text { normal tissue. }\end{array}$ & $\begin{array}{l}\text { miR- } 429 \text { deregulation is } \\
\text { involved in the development, } \\
\text { progression, prognosis, dif- } \\
\text { ferentiation, proliferation, } \\
\text { metastasis, apoptosis and drug } \\
\text { resistance of CRC. }\end{array}$ & $\begin{array}{l}\text { miR- } 429 \text { inhibits proliferation, migration } \\
\text { and invasion of CRC cells by targeting } \\
\text { Onecut } 2 \text { and PAK6/coflin; miR- } 429 \text { pro- } \\
\text { motes proliferation, metastasis and sup- } \\
\text { presses apoptosis of CRC cells by targeting } \\
\text { HOXA5 and SOX2. }\end{array}$ & $12,50-57$ \\
\hline $\begin{array}{l}\text { Hepatocellular } \\
\text { carcinoma (HCC) }\end{array}$ & $\begin{array}{l}\text { Downregulation: miR-429 is down- } \\
\text { regulated in HBV-HCC tissue and } \\
\text { HepG2.2.15 cells compared to normal } \\
\text { liver tissue and LO2 cells. } \\
\text { Upregulation: miR- } 429 \text { is upregulated } \\
\text { in HCC tissue and SMMC-7721 cells } \\
\text { compared to normal liver tissue and } \\
\text { liver cells QSG-7701. }\end{array}$ & $\begin{array}{l}\text { miR- } 429 \text { serves as a potential } \\
\text { indicator for development, } \\
\text { progression, prognosis and } \\
\text { recurrence of HCC; miR- } 429 \\
\text { plays a role in HCC cell prolif- } \\
\text { eration, apoptosis, migration } \\
\text { and invasion. }\end{array}$ & $\begin{array}{l}\text { miR-429 decreases proliferation and } \\
\text { increases apoptosis of HepG } 2.2 .15 \text { cells } \\
\text { by directly targeting NOTCH1; miR- } 429 \\
\text { regulates HCC cell migration and invasion } \\
\text { by directly targeting CRKL via inhibiting } \\
\text { Raf/MEK/ERK-EMT pathway or targeting } \\
\text { PTEN/PI3K/AKT/ } \beta \text {-catenin pathway. }\end{array}$ & $9,58-60$ \\
\hline Bladder cancer & $\begin{array}{l}\text { Downregulation: miR- } 429 \text { is higher } \\
\text { in specimens from alive patients than } \\
\text { expired patients in both of 5-year OS } \\
\text { and 5-year RFS, miR- } 429 \text { expression } \\
\text { is lower in high grade bladder cancer } \\
\text { cells than low grade bladder cancer } \\
\text { cells. } \\
\text { Upregulation: miR- } 429 \text { expression is } \\
\text { increased in bladder cancer tissues } \\
\text { compared with matched normal uro- } \\
\text { thelium tissues. }\end{array}$ & $\begin{array}{l}\text { miR- } 429 \text { overexpression inhib- } \\
\text { its migration and invasion of } \\
\text { T24 cells; miR- } 429 \text { overexpres- } \\
\text { sion promotes proliferation and } \\
\text { inhibits apoptosis of T } 24 \text { and } \\
5637 \text { cells; miR- } 429 \text { upregula- } \\
\text { tion positively correlated with } \\
\text { bladder cancer clinical patho- } \\
\text { logic grading, TNM stage and } \\
\text { low survival of patients. }\end{array}$ & $\begin{array}{l}\text { miR- } 429 \text { decreases migratory and invasive } \\
\text { of bladder cancer through restoring the } \\
\text { E-cadherin expression and inhibiting the } \\
\text { MMP-2 activity; miR- } 429 \text { promotes prolif- } \\
\text { eration and decreases apoptosis of bladder } \\
\text { cancer cells via inhibiting CDKN2B. }\end{array}$ & $15,61,62$ \\
\hline Ovarian cancer (OC) & $\begin{array}{l}\text { Downregulation: miR- } 429 \text { is down- } \\
\text { regulated in OC tissue compared to } \\
\text { paired adjacent nontumorous tissue; } \\
\text { miR- } 429 \text { expression level is lower in } \\
\text { high invasive and metastatic potential } \\
\text { cells relative to low invasive and meta- } \\
\text { static potential cells. } \\
\text { Upregulation: The serum level of miR- } \\
429 \text { is upregulated in EOC patients } \\
\text { compared with healthy women. }\end{array}$ & $\begin{array}{l}\text { miR- } 429 \text { is involved in develop- } \\
\text { ment, progression, prognosis, } \\
\text { migration, invasion and drug } \\
\text { resistance. }\end{array}$ & $\begin{array}{l}\text { miR- } 429 \text { inhibits OC cell migration and } \\
\text { invasion by inducing MET; miR- } 429 \\
\text { affects OC cell drug resistance by directly } \\
\text { targeting KIAA0101 via regulating Wnt/ } \beta \text { - } \\
\text { catenin pathway. }\end{array}$ & $\begin{array}{l}7,11 \\
63-66\end{array}$ \\
\hline
\end{tabular}

miR-429 was significantly downregulated in liver metastatic tissues compared with their paired primary CRC tissues [52]. miR-429 might be a new candidate biomarker for CRC.

miR-429 downregulation was involved in proliferation and metastasis of CRC. miR-429 inhibited the proliferation, migration and invasion of HT-29, SW480, SW620, LOVO cells in vitro and in vivo, vice versa [53], and reversed TGF-b-induced EMT changes. Furthermore, miR-429 inhibited proliferation, migration and invasion of CRC cells by targeting Onecut2 and PAK6/coflin 1 (CFL1). Therefore, miR-429 might be a potential molecular target for the treatment of CRC.

miR-429 upregulation in CRC. However, miR-429 expression was upregulated in human CRC tissues compared to adjacent non-cancerous tissues, and the high miR-429 expression was significantly associated with tumor size, LNM, TNM stage and poor prognosis [12, 54-56]. Meanwhile, miR-429 overexpression enhanced proliferation and migra- tion of HT29 and HCT116 cells, and miR-429 downregulation inhibited proliferation and migration of LOVO cell in vitro and in vivo [56]. Functionally, miR-429 exerted oncogenic effect, at least in part, by directly repressing HOXA5 expression regulated proliferation and metastasis of CRC cells, and miR-429 overexpression suppressed HT-29 cell apoptosis by directly targeting SOX2 $[12,56]$.

Furthermore, miR-429 overexpression was associated with poor response to 5-FU-based chemotherapy in patients with CRC. For patients receiving 5-FU-based treatment, the expression level of miR-429 was significantly higher in patients not responding to treatment compared to patients responding to treatment. Moreover, the proportions of patients that did not experience response to therapy were higher in primary tumors with high miR-429 expression levels as compared with primary tumors with low miR-429 expression levels. Thus, miR-429 might be an independent prognostic indicator for chemo-response to 5-FU therapy 
among CRC patients [54], indicating miR-429 could affect the chemo-sensitivity of CRC patients to 5-FU therapy. Evodiamine, Berberine and Niclosamide could potentially inhibit the progression of CRC by downregulating the expression level of miR-429 [57]. Taken together, miR-429 could play an oncogenic role in the cellular processes of CRC.

\section{Hepatocellular carcinoma}

miR-429 downregulation in HCC. miR-429 may act as a candidate tumor suppressor gene in HCC. miR-429 was downregulated in HBV-HCC tissues and HepG2.2.15 cells compared to normal liver tissues and $\mathrm{LO} 2$ cells, respectively. Meanwhile, miR-429 overexpression inhibited proliferation and induced apoptosis of HepG2.2.15 cells. Also, miR-429 inhibited the secretion of HBV proteins but could not inhibit HBV replication at DNA level. Functionally, miR-429 directly targeted NOTCH1 to inhibit its expression, which resulted in decreased proliferation and increased apoptosis of HepG2.2.15 cells [9]. Our results showed that miR-429 overexpression inhibited the migration and invasion abilities of HepG2 cells, on the contrary, miR-429 knockdown promoted the migration and invasion abilities of HepG2 cells. Furthermore, miR-429 regulated HepG2 cells migration and invasion by targeting CRKL via inhibiting Raf/ MEK/ERK-EMT pathway [58].

miR-429 upregulation in HCC. miR-429 positively correlated with development and progression of HCC. miR-429 was upregulated in HCC tumor tissues and SMMC-7721 cells compared with nonmalignant adjacent liver tissues and nontumor liver cell QSG-7701, respectively, the expression level of miR-429 was significantly correlated with larger tumor size and higher AFB1-DNA adducts [59]. Meanwhile, the expression levels of miR-429 in portal vein tumor thrombus (PVTT) and HCC primary tumor (PT) tissues were higher than in normal tissues [60]. Furthermore, miR-429 overexpression was significantly associated with poorer recurrence-free survival (RFS) and OS of HCC patients. Functionally, miR-429 overexpression promoted proliferation and inhibited apoptosis of SMMC-7721 cells in vitro [59]. These results indicated that miR-429 modulated prognosis and tumorigenesis of HCC, and might be a potential tumor therapeutic target.

miR-429 might play an important role in HCC metastasis. miR-429 expression level positively associated with HCC cell metastatic capacity. miR-429 overexpression promoted migration and invasion of SMMC-7721, HCCLM3 cells, vice versa. Functionally, miR-429 affected migration and invasion of SMMC-7721, HCCLM3 cells by directly targeting the PTEN/PI3K/AKT/ $\beta$-catenin pathway [60]. miR-429 is a key inducer for HCC pathogenesis and metastasis with potential utility for tumor intervention.

\section{Bladder cancer}

miR-429 downregulation in bladder cancer. miR-429 might be used as a progression marker of bladder cancer. miR-429 expression was significantly associated with patient survival, it was higher in alive patients' specimens than expired patients with both of 5-year OS and 5-year RFS. Patients with miR-429 expression had significantly better 5-year OS and 5-year RFS rates than those without miR-429 expression [61]. miR-429 expression was lower in high grade bladder cancer cells TSGH2010 and T24 than that in low grade bladder cancer cells TSGH8301 and TSGH9202 [15]. Moreover, miR-429 associated with migration and invasion of bladder cancer cells. miR-429 overexpression inhibited migration and invasion abilities of T24 cells. Furthermore,

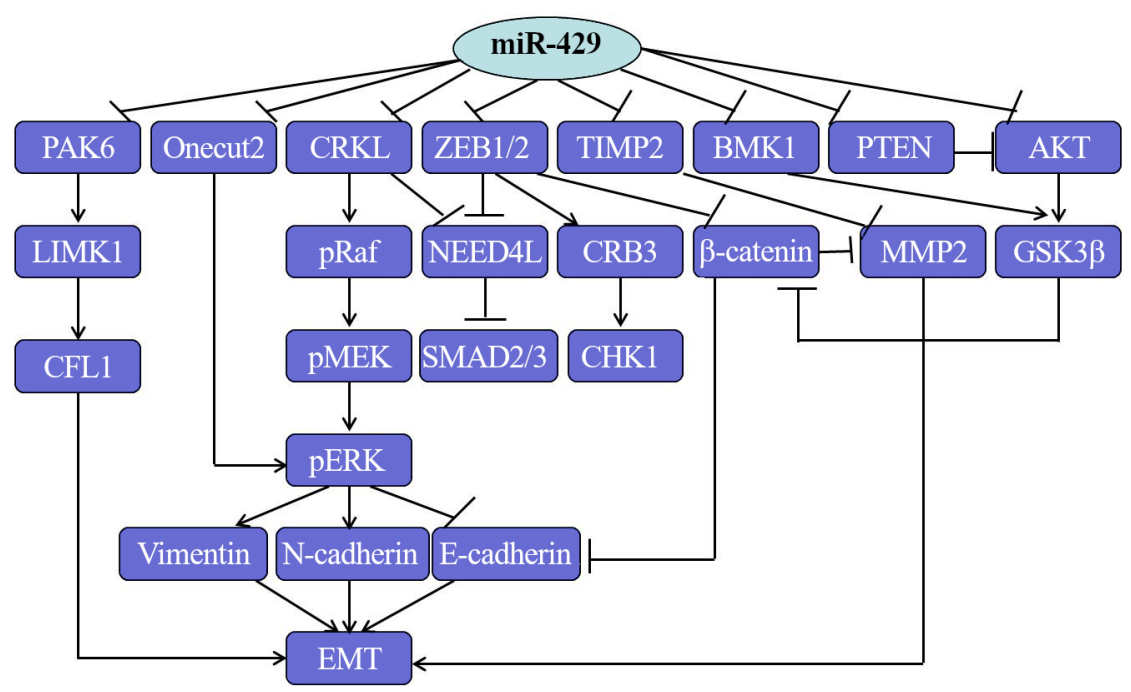

Figure 1. A schematic regulation mechanism of miR-429 on tumor cell migration and invasion. 


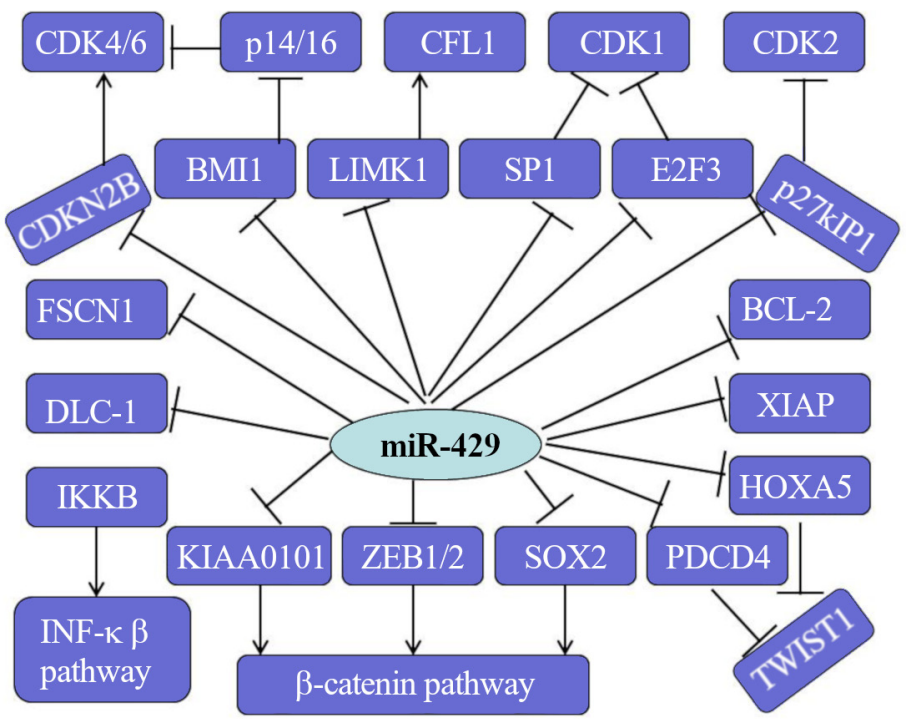

Figure 2. The potential biological action mechanisms of miR-429 on tumor cell cycle, proliferation, apoptosis and chemotherapy resistance.

miR-429 overexpression decreased ZEB1 and $\beta$-catenin expression, which resulted in upregulation of E-cadherin and inactivation of MMP-2, therefore inhibited migration and invasion of bladder cancer cells [15]. miR-429 might be used as a potential clinical prognostic and predictive marker in bladder cancer.

miR-429 upregulation in bladder cancer. In contrast, miR-429 expression was increased in bladder cancer tissues compared with matched normal urothelial tissues. Meanwhile, miR-429 upregulation was positively correlated with bladder cancer clinical pathologic grading, TNM stage and low survival of patients. Meanwhile, miR-429 overexpression promoted proliferation and inhibited apoptosis of T24 and 5637 cells in vitro and in vivo. Furthermore, miR-429 and CDKN2B were inversely expressed in bladder cancer tissues, CDKN2B downregulation also promoted T24 and 5637 cells growth and decreased apoptosis in vitro [62], indicating miR-429 promoted proliferation and decreased apoptosis of bladder cancer cell via inhibiting CDKN2B.

\section{Ovarian cancer}

miR-429 downregulation in OC. miR-429 may serve as a negative indicator for OC development and progression. miR-429 was significantly downregulated in OC tissues compared to paired adjacent non-tumor tissues, moreover, decreased expression of miR-429 associated with higher cancer recurrence, poor $O S$ and less progression-free survival (PFS) of RCC patients [7, 63]. miR-429 plays an important regulatory role in $\mathrm{OC}$ and may be used as a prognostic marker for OC outcome.

miR-429 inhibited metastatic of OC cells. miR-429 expression level was significantly lower in HEY cells with high invasive and metastatic potential relative to OVCAR3 cells with low invasive and metastatic potential. Meanwhile, miR-429 overexpression induced HEY and OCI-984 cells to undergo a morphological change from an elongated, spindle-shaped, mesenchymal phenotype to a more rounded, epithelial-like phenotype. Moreover, miR-429 overexpression inhibited ZEB1, ZEB2, FN1, TWISTI expression of mesenchymal marker and promoted E-cadherin expression of epithelial marker, indicating miR-429 inhibited OC cells migration and invasion by inducing mesenchymal-to-epithelial transition (MET) [11, 64].

miR-429 was also involved in OC drug resistance. miR-429 overexpression increased drug sensitivity of OCI-984, SKOV3 and COV644 cells to cisplatin [64, 65], moreover, miR-429 affected chemoresistance of OC cells by directly targeting ZEB1 and KIAA0101 via regulating Wnt/ $\beta$ catenin signaling pathway $[64,65]$, indicating that miR-429 in combination with platinum-based chemotherapies may be an effective strategy in reducing OC metastasis and tumor recurrence.

miR-429 upregulation in OC. On the contrary, in contrast to some other studies showing discrepant findings on miR-429 as tumor-suppressor, miR-429 can act as tumor promoter or oncogene. The serum level of miR-429 was upregulated in epithelial ovarian cancer (EOC) patients compared with healthy women, and the expression level of miR-429 positively correlated with tumor marker CA125, and differed between FIGO I-II and III-IV stages. Moreover, miR-429 was an independent predictor of OS. miR-429 overexpression inhibited migration and invasion of SKOV3 cells, while miR-429 had no impact on proliferation and apoptosis of SKOV3 cells [66]. miR-429 may be promising molecule to be targeted in the treatment of EOC. 


\section{Potential summarized \& hypothesized biological action mechanisms of miR-429 in cancers}

The overall potential action mechanisms of miR-429 in cancers were hypothesized and illustrated in Figure 1 and Figure 2. According to our summary and analysis, miR-429 regulates tumor migration and invasion mainly via mediating EMT, 1) Raf/MEK/ERK pathway: miR-429 downregulated CRKL expression at the post-transcriptional protein translation level by directly targeting its 3'-UTR, CRKL downregulation inhibited the expression level of p-Raf, p-MEK and p-ERK, and then suppressed migration and invasion through inhibiting EMT by increasing the epithelial marker E-cadherin expression, and decreasing the mesenchymal marker $\mathrm{N}$-cadherin and Vimentin expression [58]; 2) PTEN/AKT/GSK-3 $\beta / \beta$-catenin pathway: miR-429 induced the phosphorylation level of AKT and inhibited the phosphorylation level of GSK-3 $\beta$ through downregulating the PTEN protein level, and responsive subsequent $\beta$-catenin transcriptional activation, then suppressed migration and invasion by increasing E-cadherin expression [60]; 3) PAK6/ CFL1 pathway: miR-429 directly inhibited PAK6 expression, then regulated migration and invasion of tumor cells through interaction of LIMK1-CFL1 pathway [21, 51, 53]; 4) SMAD and CHK1 pathway: miR-429 had an inhibitive role in ZEB1 and CRKL expression. ZEB1 could activate CHK1 via its upregulation of CRB3. On the other hand, both ZEB1 and CRKL could impede NEED4L while increase SMAD2/3 expression, suppressing apoptosis progression. Due to CHK1, NEED4L, and SMAD2/3 regulation by ZEB1 and CRKL modulated by miR-429, migration and invasion of cervical cancer were influenced $[36]$; 5) BMK1/GSK-3 $\beta / \beta$-catenin pathway: miR-429 downregulated BMK1 expression, GSK3b phosphorylation was suppressed through BMK1 knockdown, then suppressed metastasis through increasing E-cadherin expression by inhibiting $\beta$-catenin [28]; 6) Onecut2/ERK pathway: miR-429 regulated EMT by targeting Onecut2 through ERK pathway [53]; 7) TIMP2/MMP2 pathway: miR-429 could also regulate EMT by targeting TIMP2 through MMP2 [47]; 8) ZEB/ $\beta$-catenin pathway: miR-429 also inhibited migration and invasion by targeting ZEB1/2 through $\beta$-catenin pathway $[10,11,15,20,32,36,41]$.

We also summarized the potential mechanism of miR-429 on cell cycle, proliferation, apoptosis and chemoresistance according to published literature, and we propose that miR-429 acts on tumor cell cycle, proliferation, apoptosis and chemoresistance mainly via the following detailed pathways. 1) $\beta$-catenin pathway: miR-429 regulated tumor cell proliferation, apoptosis and chemoresistance through $\beta$-catenin pathway by directly targeting KIAA0101, ZEB1/2 and SOX2 $[12,29,64,65]$; 2) INF- $\kappa \beta$ pathway: miR-429 suppressed proliferation and induced apoptosis of tumor cell by targeting IKK $\beta$ via regulating NF- $\kappa \beta$ pathway [34];3) miR-429 targeted the LIMK1/CFL1 pathway to inhibit growth of tumor cells [21]; 4) miR-429 enhanced chemosensitivity and inhibited proliferation of tumor cell via regulating TWIST1 by targeting
PDCD4 and HOXA5 [37, 64, 56]; 5) CDK pathway: miR-429 directly targeted BMI1 to promote p14 and p16 expression, then inhibited proliferation, cell cycle and induced apoptosis of tumor cells by decreasing CDK4/6. Meanwhile, miR-429 also exerted an oncogenic effect via decreasing CDK4/6, CDK1, CDK2 by targeting CDKN2B, Sp1, E2F3, p27kIP1, respectively $[16,18,45,62]$; 6) Additionally, miR-429 inhibited proliferation, cell cycle and induced apoptosis of tumor cells by directly targeting FSCN1, DLC-1, BCL-2 and XIAP $[22,25,27,31,48]$.

\section{Discussion}

The abnormal expressions of miR-429 are closely associated with RCC, BC, GC, GBM, EC, osteosarcoma, OSCC, CC, pancreatic cancer, TSCC, nephroblastoma, NPC, soft tissue sarcomas, EmCa, CaP, LC, CRC, HCC, bladder cancer and OC, as summarized in Tables 1-3. miR-429 shows tumor type-specific expression patterns and exhibits vital roles in tumor development, progression, prognosis, metastasis, apoptosis and drug resistance. miR- 429 could regulate tumor malignant behavior by directly targeting a variety of molecules, EMT involved in migration and invasion of tumor, according to our analysis and summary, miR-429 regulates tumor migration and invasion mainly via mediating EMT by targeting a variety of molecules through ERK, Wnt and Akt signaling pathway. While, there no a systematic pathway of miR-429 on tumor cell cycle, proliferation, apoptosis and chemotherapy resistance, according to published literature, we understand that miR-429 regulates tumor cell cycle, proliferation, apoptosis and chemotherapy resistance mainly via INF- $\kappa \beta$, Wnt and CDK signaling pathway by targeting a variety of molecules.

The aberrant expression level of miR-429 could serve as a potential biomarker for the diagnosis, treatment and prognosis of certain cancers. Tumor cell necrosis and apoptosis are the main sources of miRNAs in the blood, using qRT-PCR detect the expression level of miR-429 in blood for diagnosis and prognosis of tumors, meanwhile, we could also detect the expression level of miR-429 in saliva, urine, semen and feces, furthermore, miR-429 aberrantly expressed in tumor tissues, imaging technology are used for detecting the expression level of miR-429 in tumor tissues. However, miR-429 specifically functions either as a tumor suppressor or promoter candidate for certain cancers depending on the particular type of tumor cells/tissues, the expression of miR-429 is only one of indicator for diagnosis, treatment and prognosis of certain tumors, so, we couldn't diagnose of certain cancer only based on the expression of miR-429 alone, we should combine miR-429 expression level with many other clinical diagnostic methods and indicators to make conclusion.

Therapy can be targeted to miRNAs in two ways: miRNA reduction and miRNA replacement. In miR-429 reduction treatment, single-stranded locked nucleic acid (LNA) 
molecules (anti-miR-429) bind to miR-429 complementarily, preventing the miR-429 from binding to target mRNAs. In miR-429 replacement treatment, miR-429 is reintroduced by the use of a miR-429 mimic. These double-stranded miR-429 mimics can either be modified on the complementary strand or encapsulated in nanoparticles to increase their stability. The delivery of anti-miR-429 and miR-429 mimics can be improved with nanoparticles conjugated to antibodies or cancer-specific ligands.

miRNAs negatively regulate gene expression posttranscriptionally by inhibiting translation and causing degradation of target mRNA. Each miRNA can potentially regulate hundreds of mRNAs. miR-429 could directly target ZEB1, ZEB2, Sp1, BMI1, E2F3, KIAA0101, PAK6, Onecut2, SOX2, Bcl-2, BMK1, XIAP, c-myc, SP1, PTEN, RASSF8, TIMP2, DLC-1, p27Kip1, NOTCH1, CRKL molecules, etc. miR-429 might specifically function either as a tumor suppressor or promoter candidate for certain cancers depending on the particular type of tumor cells/tissues. However, as it is not clear whether miR-429 targets have cell and tissue specificity, we will further study the problem.

Many miRNAs were identified to be involved in drug resistance of cancer. The regulation of certain miRNA expression could partially improve the response of tumor cells to chemotherapy and significantly enhance the antitumor properties of specific drugs. miRNA involved in drug resistance has been ascribed to the alteration of drug transporters leading to efflux of anticancer agents, modification of autophagy/ apoptosis to enhance survival, promotion of growth factors to disturb associated signal pathways and activation of EMT process to promote metastasis. According to our summary, miR-429 could mediate $\delta$-tocotrienol-, 5-Fluorouracil-, temozolomide-, cisplatin-, nintedanib-, Evodiamine-, Berberine-, Niclosamide-induced apoptosis and affect drug sensitivity of BC, GC, GBM, EmCa, LC, CRC, OC cells by targeting Bcl-2, XIAP, SOX2, ZEB1 and KIAA010, indicating miR-429 could play a role in the development of multidrug resistance in cancer cells, at least in part through the modulation of apoptosis by targeting Bcl-2, XIAP, SOX2, ZEB1 and KIAA0101. The knowledge of the emerging role of miR-429 in drug resistance is very helpful for developing personalized antitumor regimens, as well as to establish novel therapeutic strategies to reverse the resistance of tumors in combination with chemotherapeutic agents. miRNA mimics and antagonists are single-stranded RNAs capable of imitating and silencing, however, these mimics or antagomirs have not yet been used to a large degree in clinical trials. Although there are still multiple challenges to overcome before miRNA therapeutics can be used clinically, it is predicted that in the near future, miRNA-based approaches may provide important advances in overcoming drug resistance and improving chemotherapy response and quality of life for cancer patients. Further studies are needed to discover more miR-429 targets and to acquire a better understanding of the mechanisms of multidrug resistance in cancer.
Taken together, the study on the role of miR-429 in cancer cells/tissues has great potential value not only for understanding tumor progression, but also for developing novel diagnostic and therapeutic approaches.

Acknowledgements: This work was supported by grants from National Natural Science Foundation of China (81272186, 81050010, 31900517) and Key Laboratory of the Department of Education of Liaoning (LS2010050). Provincial Natural Science Foundation of Liaoning (LQ2017001, 20181550168).

\section{References}

[1] FANG YX, GAO WQ. Roles of microRNAs during prostatic tumorigenesis and tumor progression. Oncogene 2014; 33: 135-147. https://doi.org/10.1038/onc.2013.54

[2] CALIN GA, CROCE CM. MicroRNA signatures in human cancers. Nat Rev Cancer 2006; 6: 857-866. https://doi. org/10.1038/nrc1997

[3] BARTEL DP. MicroRNAs: target recognition and regulatory functions. Cell 2009; 136: 215-233. https://doi.org/10.1016/j. cell.2009.01.002

[4] VOLINIA S, CALIN GA, LIU CG, AMBS S, CIMMINO A et al. A microRNA expression signature of human solid tumors defines cancer gene targets. Proc Natl Acad Sci U S A 2006; 103: 2257-2261. https://doi.org/10.1073/ pnas.0510565103

[5] ZIMMERMAN AL, WU S. MicroRNAs, cancer and cancer stem cells. Cancer Lett 2011; 300: 10-19. https://doi. org/10.1016/j.canlet.2010.09.019

[6] CALLEGARI E, GRAMANTIERI L, DOMENICALI M, D’ABUNDO L, SABBIONI S et al. MicroRNAs in liver cancer: a model for investigating pathogenesis and novel therapeutic approaches. Cell Death Differ 2015; 22: 46-57. https:// doi.org/10.1038/cdd.2014.136

[7] HU X, MACDONALD DM, HUETTNER PC, FENG Z, EL NAQA IM et al. A miR-200 microRNA cluster as prognostic marker in advanced ovarian cancer. Gynecol Oncol 2009; 114: 457-464. https://doi.org/10.1016/j.ygyno.2009.05.022

[8] SUN T, WANG C, XING J, WU D. miR-429 modulates the expression of c-myc in human gastric carcinoma cells. Eur J Cancer 2011; 47: 2552-2259. https://doi.org/10.1016/j. ejca.2011.05.021

[9] GAO H, LIU C. miR-429 represses cell proliferation and induces apoptosis in HBV-related HCC. Biomed Pharmacother 2014; 68: 943-949. https://doi.org/10.1016/j.biopha.2014.09.005

[10] LIU X, LIU Y, WU S, SHI X, LI L et al. Tumor-suppressing effects of miR-429 on human osteosarcoma. Cell Biochem Biophys 2014; 70: 215-224. https://doi.org/10.1007/s12013014-9885-8

[11] CHEN J, WANG LJ, MATYUNINA LV, HILL CG, MCDONALD JF. Overexpression of miR-429 induces mesenchymal-to-epithelial transition (MET) in metastatic ovarian cancer cells. Gynecol Oncol 2011; 121: 200-205. https://doi. org/10.1016/j.ygyno.2010.12.339 
[12] LI J, DU L, YANG Y, WANG C, LIU H et al. MiR-429 is an independent prognostic factor in colorectal cancer and exerts its anti-apoptotic function by targeting SOX2. Cancer Lett 2013; 329: $\quad 84-90 . \quad$ https://doi.org/10.1016/j.canlet.2012.10.019

[13] SNOWDON J, ZHANG X, CHILDS T, TRON VA, HARRIET F. The microRNA-200 family is upregulated in endometrial carcinoma. PLoS One 2011; 6: e22828. https://doi. org/10.1371/journal.pone.0022828

[14] SHI J, MENG L, SUN MZ, GUO C, SUN X et al. CRKL knockdown promotes in vitro proliferation, migration and invasion, in vivo tumor malignancy and lymph node metastasis of murine hepatocarcinoma Hca-P cells. Biomed Pharmacother 2015; 71: 84-90. https://doi.org/10.1016/j. biopha.2015.02.022

[15] WU CL, HO JY, CHOU SC, YU DS. MiR-429 reverses epithelial-mesenchymal transition by restoring E-cadherin expression in bladder cancer. Oncotarget 2016; 7: 2659326603. https://doi.org/10.18632/oncotarget.8557

[16] QIU M, LIANG Z, CHEN L, TAN G, WANG K et al. MicroRNA-429 suppresses cell proliferation, epithelial-mesenchymal transition, and metastasis by direct targeting of BMI1 and E2F3 in renal cell carcinoma. Urol Oncol 2015; 33: 332.e9-e18. https://doi.org/10.1016/j.urolonc.2015.03.016

[17] MACHACKOVA T, MLCOCHOVA H, STANIK M, DOLEZEL J, FEDORKO M et al. MiR-429 is linked to metastasis and poor prognosis in renal cell carcinoma by affecting epithelial-mesenchymal transition. Tumour Biol 2016; 37: 14653-14658. https://doi.org/10.1007/s13277-016-5310-9

[18] WU D, NIU X, PAN H, ZHOU Y, ZHANG Z et al. Tumorsuppressing effects of microRNA-429 in human renal cell carcinoma via the downregulation of Sp1. Oncol Lett 2016; 12: 2906-2911. https://doi.org/10.3892/ol.2016.4953

[19] XUF, HE H, HUANG W, LINY,LUOS et al. Decreased expression of MicroRNA-200 family in human breast cancer is associated with lymph node metastasis. Clin Transl Oncol 2016; 18: 283-288. https://doi.org/10.1007/s12094-015-1364-1

[20] YE ZB, MA G, ZHAO YH, XIAO Y, ZHANG Y et al. miR429 inhibits migration and invasion of breast cancer cells in vitro. Int J Oncol 2015; 46: 531-538. https://doi.org/10.3892/ ijo.2014.2759

[21] LI D, WANG H, SONG H, XU H, ZHAO B et al. The microRNAs miR-200b-3p and miR-429-5p target the LIMK1/ CFL1 pathway to inhibit growth and motility of breast cancer cells. Oncotarget 2017; 8: 85276-85289. https://doi. org/10.18632/oncotarget.19205

[22] WANG C, JU H, SHEN C, TONG Z. miR-429 mediates delta-tocotrienol-induced apoptosis in triple-negative breast cancer cells by targeting XIAP. Int J Clin Exp Med 2015; 8: 15648-15656.

[23] SHENG N, ZHANG L, YANG S. MicroRNA-429 decreases the invasion ability of gastric cancer cell line BGC-823 by downregulating the expression of heparanase. Exp Ther Med 2018; 15: 1927-1933. https://doi.org/10.3892/ etm.2017.5608

[24] NI J, YANG Y, LIU D, SUN H, JIN S et al. MicroRNA-429 inhibits gastric cancer migration and invasion through the downregulation of specificity protein 1 . Oncol Lett 2017; 13: 3845-3849. https://doi.org/10.3892/ol.2017.5869
[25] ZHANG M, DONG BB, LU M, ZHENG MJ, CHEN H et al. miR-429 functions as a tumor suppressor by targeting FSCN1 in gastric cancer cells. Onco Targets Ther 2016; 9: 1123-1133. https://doi.org/10.2147/OTT.S91879

[26] LIU D, XIA P, DIAO D, CHENG Y, ZHANG H et al. MiRNA-429 suppresses the growth of gastric cancer cells in vitro. J Biomed Res 2012; 26: 389-393. https://doi.org/10.7555/ JBR.26.20120029

[27] ZHU P, Zhang JP, ZHU JF, SHI J, ZHU QW, GAO YY. MiR429 induces gastric carcinoma cell apoptosis through Bcl-2. Cell Physiol Biochem 2015;37:1572-80.

[28] CHEN W, ZHANG B, GUO W, GAO L, SHI L et al. miR-429 inhibits glioma invasion through BMK1 suppression. J Neurooncol 2015; 125: 43-54. https://doi.org/10.1007/s11060015-1887-X

[29] DONG H, HAO X, CUI B, GUO M. MIR-429 suppresses glioblastoma multiforme by targeting SOX2. Cell Biochem Funct 2017; 35: 260-268. https://doi.org/10.1002/cbf.3271

[30] CHENG Z, LI Z, MA K, LI X, TIAN N et al. Long Non-coding RNA XIST promotes glioma tumorigenicity and angiogenesis by acting as a molecular sponge of miR-429. J Cancer 2017; 8: 4106-4116. https://doi.org/10.7150/jca.21024

[31] WANG Y, LI M, ZANG W, MA Y, WANG N et al. MiR-429 up-regulation induces apoptosis and suppresses invasion by targeting Bcl-2 and SP-1 in esophageal carcinoma. Cell Oncol(Dordr) 2013; 36: 385-394. https://doi.org/10.1007/ s13402-013-0144-6

[32] DENG Y, LUAN FJ, ZENG L, ZHANG Y, MA K. MIR-429 suppresses the progression and metastasis of osteosarcoma by targeting ZEB1. EXCLI J 2017; 16: 618-627. https://doi. org/10.17179/excli2017-258

[33] LEI W, LIU YE, ZHENG Y, QU L. MiR-429 inhibits oral squamous cell carcinoma growth by targeting ZEB1. Med Sci Monit 2015; 21: 383-389. https://doi.org/10.12659/ MSM.893412

[34] FAN JY, FAN YJ, WANG XL, XIE H, GAO HJ et al. miR-429 is involved in regulation of NF- $\kappa \beta$ activity by targeting IKK $\beta$ and suppresses oncogenic activity in cervical cancer cells. FEBS Lett 2017; 591: 118-128. https://doi.org/10.1002/18733468.12502

[35] SHEN F, ZHENG H, ZHOU L, LI W, XU X. Overexpression of MALAT1 contributes to cervical cancer progression by acting as a sponge of miR-429. J Cell Physiol 2019; 234: 11219-11226. https://doi.org/10.1002/jcp.27772

[36] WANG Y, DONG X, HU B, WANG XJ, WANG Q et al. The effects of Micro-429 on inhibition of cervical cancer cells through targeting ZEB1 and CRKL. Biomed Pharmacother 2016; 80: 311-321. https://doi.org/10.1016/j.biopha.2016.03.035

[37] YU G, JIA B, CHENG Y, ZHOU L, QIAN B et al. MicroRNA-429 sensitizes pancreatic cancer cells to gemcitabine through regulation of PDCD4. Am J Transl Res 2017; 9: 5048-5055.

[38] LIU D, SONG L, DAI Z, GUAN H, KANG H et al. MiR-429 suppresses neurotrophin-3 to alleviate perineural invasion of pancreatic cancer. Biochem Bioph Res Commun 2018; 505: 1077-1083. https://doi.org/10.1016/j.bbrc.2018.09.147 
[39] MA L, WANG Q, GONG Z, XUE L, ZUO Z. Long noncoding RNA gihcg enhanced tongue squamous cell carcinoma progression through regulating miR-429. J Cell Biochem 2018; 119: 9064-9071. https://doi.org/10.1002/jcb.27164

[40] WANG HF, WANG WH, ZHUANG HW, XU M. MiR-429 regulates the proliferation and apoptosis of nephroblastoma cells through targeting c-myc. Eur Rev Med Pharmacol Sci 2018; 22: 5172-5179. https://doi.org/10.26355/eurrev_201808_15713

[41] WANG F, JIANG C, SUN Q, YAN F, WANG L et al. Downregulation of miR-429 and inhibition of cell migration and invasion in nasopharyngeal carcinoma. Mol Med Rep 2016; 13: 3236-3242. https://doi.org/10.3892/mmr.2016.4940

[42] SAMANTARRAI D, MALLICK B. miR-429 inhibits metastasis by targeting KIAA0101 in Soft Tissue Sarcoma. Exp Cell Res 2017; 1: 33-39. https://doi.org/10.1016/j.yexcr.2017.04.017

[43] LEE JW, PARK YA, CHOI JJ, LEE YY, KIM CJ et al. The expression of the miRNA-200 family in endometrial endometrioid carcinoma. Gynecol Oncol 2011; 120: 56-62. https:// doi.org/10.1016/j.ygyno.2010.09.022

[44] YONEYAMA K, ISHIBASHI O, KAWASE R, KUROSE K, TAKESHITA T. miR-200a, miR-200b and miR-429 are oncomiRs that target the PTEN gene in endometrioid endometrial carcinoma. Anticancer Res 2015; 35: 1401-1410.

[45] OUYANG Y, GAO P, ZHU B, CHEN X, LIN F et al. Downregulation of microRNA-429 inhibits cell proliferation by targeting p27Kip1 in human prostate cancer cells. Mol Med Rep 2015; 11: 1435-1441. https://doi.org/10.3892/ mmr.2014.2782

[46] LIN K, XU T, HE BS, PAN YQ, SUN HL et al. MicroRNA expression profiles predict progression and clinical outcome in lung adenocarcinoma. Onco Targets Ther 2016; 9: 56795692. https://doi.org/10.2147/OTT.S111241

[47] LANG Y, XU S, MA J, WUA J, JIN S et al. MicroRNA-429 induces tumorigenesis of human non-small cell lung cancer cells and targets multiple tumor suppressor genes. Biochem Biophys Res Commun 2014; 450: 154-159. https://doi. org/10.1016/j.bbrc.2014.05.084

[48] XIAO P, LIU W, ZHOU H. miR-429 promotes the proliferation of non-small cell lung cancer cells via targeting DLC1. Oncol Lett 2016; 12: 2163-2168. https://doi.org/10.3892/ ol.2016.4904

[49] NISHIJIMA N, SEIKE M, SOENO C, CHIBA M, MIYANAGA A et al. MiR-200/ZEB axis regulates sensitivity to nintedanib in non-small cell lung cancer cells. Int J Oncol 2016; 48: 937-944. https://doi.org/10.3892/ijo.2016.3331

[50] SUN Y, SHEN S, TANG H, XIANG J, PENG Y et al. miR-429 identified by dynamic transcriptome analysis is a new candidate biomarker for colorectal cancer prognosis. OMICS 2014; 18: 54-64. https://doi.org/10.1089/ omi.2012.0132

[51] TIAN X, WEI Z, WANG J, LIU P, QIN Y et al. MicroRNA-429 inhibits the migration and invasion of colon cancer cells by targeting PAK6/cofilin signaling. Oncol Rep 2015; 34: 707-714. https://doi.org/10.3892/or.2015.4039
[52] CRISTOBAL I, RINCON R, MANSO R, CARAMES C, AGUILERA O et al. Deregulation of miR-200b, miR-200c and miR-429 indicates its potential relevant role in patients with colorectal cancer liver metastasis. J Surg Oncol 2014; 110: 484-485. https://doi.org/10.1002/jso.23661

[53] SUN Y, SHEN S, LIU X, TANG H, WANG Z et al. MiR-429 inhibits cells growth and invasion and regulates EMT-related marker genes by targeting Onecut 2 in colorectal carcinoma. Mol Cell Biochem 2014; 390: 19-30. https://doi.org/10.1007/ s11010-013-1950-x

[54] DONG SJ, CAI XJ, LI SJ. The clinical significance of miR429 as a predictive biomarker in colorectal cancer patients receiving 5-Fluorouracil treatment. Med Sci Monit 2014; 22: 3352-3361. https://doi.org/10.12659/msm.900674

[55] LIU H, HUANG C, WU L, WEN B. Effect of evodiamine and berberine on miR-429 as an oncogene in human colorectal cancer. Onco Targets Ther 2016; 9: 4121-4127. https://doi. org/10.2147/OTT.S104729

[56] HAN Y, ZHAO Q, ZHOU J, SHI R. miR-429 mediates tumor growth and metastasis in colorectal cancer. Am J Cancer Res 2017; 7: 218-233.

[57] SULIMAN MA, ZHANG Z, NA H, RIBEIRO AL, ZHANG Y et al. Niclosamide inhibits colon cancer progression through downregulation of the Notch pathway and upregulation of the tumor suppressor miR-200 family. Int J Mol Med 2016; 38: 776-784. https://doi.org/10.3892/ijmm.2016.2689

[58] GUO C, ZHAO D, ZHANG Q, LIU S, SUN MZ. miR-429 suppresses tumor migration and invasion by targeting CRKL in hepatocellular carcinoma via inhibiting Raf/MEK/ERK pathway and epithelial-mesenchymal transition. Sci Rep 2018; 8: 2375. https://doi.org/10.1038/s41598-018-20258-8

[59] HUANG XY, YAO JG, HUANG HD, WANG C, MA Y et al. MicroRNA-429 modulates hepatocellular carcinoma prognosis and tumorigenesis. Gastroenterol Res Pract 2013; 2013: 804128. https://doi.org/10.1155/2013/804128

[60] TANG J, LI L, HUANG W, SUI C, YANG Y et al. MiR-429 increases the metastatic capability of HCC via regulating classic Wnt pathway rather than epithelial-mesenchymal transition. Cancer Lett 2015; 364: 33-43. https://doi.org/10.1016/j. canlet.2015.04.023

[61] WU CL, HO JY, HUNG SH, YU DS. miR-429 expression in bladder cancer and its correlation with tumor and clinical outcome. Kaohsiung J Med Sci 2018; 34: 335-340. https:// doi.org/10.1016/j.kjms.2018.01.001

[62] YANG JG, LIU YC, HE AB, LIU YH, WU JT et al. HsamiR-429 promotes bladder cancer cell proliferation via inhibiting CDKN2B. Oncotarget 2017; 8: 68721-68729. https://doi.org/10.18632/oncotarget.19878

[63] ZOU J, LIU L, WANG Q, YIN F, YANG Z et al. Downregulation of miR-429 contributes to the development of drug resistance in epithelial ovarian cancer by targeting ZEB1. Am J Transl Res 2017; 9: 1357-1368.

[64] WANG LJ, MEZENCEV R, SVAJDLER M, BENIGNO BB, MCDONALD JF. Ectopic over-expression of miR-429 induces mesenchymal-to-epithelial transition (MET) and increased drug sensitivity in metastasizing ovarian cancer cells. Gynecol Oncol 2014; 134: 96-103. https://doi.org/10.1016/j. ygyno.2014.04.055 
[65] CHEN H, XIA B, LIU T, LIN M, LOU G. KIAA0101, a target gene of miR-429, enhances migration and chemoresistance of epithelial ovarian cancer cells. Cancer Cell Int 2016; 16: 74. https://doi.org/10.1186/s12935-016-0353-y
[66] MENG X, JOOSSE SA, MULLER V, TRILLSCH F, MILDELANGOSCH K et al. Diagnostic and prognostic potential of serum miR-7, miR-16, miR-25, miR-93, miR-182, miR-376a and miR-429 in ovarian cancer patients. Br J Cancer 2015; 113: 1358-1366. https://doi.org/10.1038/bjc.2015.340 